\title{
Methicillin-resistant staphylococcal contamination of cellular phones of personnel in a veterinary teaching hospital
}

Timothy Julian ${ }^{1}$, Ameet Singh ${ }^{2 *}$, Joyce Rousseau ${ }^{1}$ and J Scott Weese ${ }^{1}$

\begin{abstract}
Background: Hospital-associated infections are an increasing cause of morbidity and mortality in veterinary patients. With the emergence of multi-drug resistant bacteria, these infections can be particularly difficult to eradicate. Sources of hospital-associated infections can include the patients' own flora, medical staff and inanimate hospital objects. Cellular phones are becoming an invaluable feature of communication within hospitals, and since they are frequently handled by healthcare personnel, there may be a potential for contamination with various pathogens. The objective of this study was to determine the prevalence of contamination of cellular phones (hospital issued and personal) carried by personnel at the Ontario Veterinary College Health Sciences Centre with methicillin-resistant Staphylococcus pseudintermedius (MRSP) and methicillin-resistant Staphylococcus aureus (MRSA).

Results: MRSP was isolated from 1.6\% (2/123) and MRSA was isolated from 0.8\% (1/123) of cellular phones. Only $21.9 \%(27 / 123)$ of participants in the study indicated that they routinely cleaned their cellular phone.

Conclusions: Cellular phones in a veterinary teaching hospital can harbour MRSP and MRSA, two opportunistic pathogens of significant concern. While the contamination rate was low, cellular phones could represent a potential source for infection of patients as well as infection of veterinary personnel and other people that might have contact with them. Regardless of the low incidence of contamination of cellular phones found in this study, a disinfection protocol for hospital-issued and personal cellular phones used in veterinary teaching hospitals should be in place to reduce the potential of cross-contamination.
\end{abstract}

Keywords: Cellular phone, Methicillin-resistant staphylococcus, Veterinary, Contamination

\section{Background}

Nosocomial or hospital-associated infections (HAIs) are an increasing cause of morbidity and mortality in human and veterinary medicine [1-4]. Multi-drug resistant (MDR) bacteria are commonly implicated in HAIs and can be challenging to eliminate [1-4]. Sources of HAI can include medical staff, the patients' own flora and inanimate hospital objects [5,6]. Hands of healthcare personnel are commonly contaminated with opportunistic pathogens and poor hand hygiene compliance is thought to be an important factor in the pathogenesis of HAIs [7]. Contaminated hands can result in direct transfer of pathogens to patients,

\footnotetext{
* Correspondence: amsingh@uoguelph.ca

${ }^{2}$ Department of Clinical Studies, Ontario Veterinary College,

University of Guelph, Guelph, ON N1G 2W1, Canada

Full list of author information is available at the end of the article
}

as well as contamination of inanimate objects (fomites). Any items that have frequent hand contact, especially in the absence of routine hand hygiene practices, are at high risk of becoming contaminated. Cellular phones (CPs) have become an indispensable accessory of today's society and they are being used extensively in a hospital setting to optimize patient care and client communications. However, CPs are commonly handled (irrespective of the cleanliness of hands), rarely disinfected and could harbour pathogenic bacteria. Concerns regarding bacterial contamination associated with the use of CP's within the hospital environment have been raised in human medicine, and studies of human healthcare worker CPs have reported contamination of $9-43 \%$ of CPs with bacteria known to cause HAIs [8-18]. Comparable data are not available for veterinary medicine.

\section{C) Biomed Central}


Methicillin-resistant S. aureus (MRSA) is a critically important hospital-associated pathogen in humans [19] and has been found on $1.9-10 \%$ of CPs sampled in hospitals [8-18]. It is also a significant concern in companion animals, both as a cause of HAI [1-3,20] and the potential for zoonotic transmission to veterinary personnel $[21,22]$. Of greater relevance from an animal health aspect is methicillin-resistant $S$. pseudintermedius, which has rapidly emerged as a leading cause of various opportunistic infections, including pyoderma $[23,24]$ and surgical site infection [1-3].

The purpose of this study was to determine the MRSA and MRSP contamination rate of CPs used by personnel in the Ontario Veterinary College Health Sciences Centre (OVCHSC) and to identify factors associated with contamination. In this study we used electrostatic cloths to recover bacteria from CPs. This methodology has previously been described for the recovery of bacteria from inanimate objects [25-27]. This method was chosen because electrostatic cloths are easy to use, inexpensive and readily available. Furthermore, a standardized sampling technique for the recovery of bacteria from inanimate objects does not exist and the sensitivity of bacterial recovery from various techniques such as contact plates, electrostatic cloths and cottontipped swabs is unknown.

\section{Methods}

\section{Sample collection and study population}

This cross-sectional study was conducted from August to September 2011 at the OVCHSC. Hospital personnel, including veterinary students, technicians, residents/interns and clinical faculty were recruited for participation in this study. Upon verbal consent, participants' CPs (hospitalissued and/or personal) were sampled and a self-administered questionnaire was completed. The questionnaire characterized the participants' position in the hospital, frequency of $\mathrm{CP}$ cleaning, and whether the personal $\mathrm{CP}$ (if present) was used while in the OVCHSC. This study was approved by the University of Guelph Research Ethics Board.

\section{Microbiological analysis}

Samples were collected by wiping an electrostatic cloth (Swiffer ${ }^{\circledR}$, Procter \& Gamble, Cincinnati, OH, USA) along all surfaces of the CP using a gloved hand [25-27]. After sampling, the cloth was placed into a pre-labeled sterile bag for later inoculation. All samples were collected by the same individual (TJ) and gloves were changed between each sample. To investigate potential sources of sampling contamination, electrostatic cloth samples were also collected from the hands and forearms of the individual (TJ) performing the sampling, the box containing the gloves, the clipboard and questionnaire sheets. During each sampling period, new, unused, electrostatic cloths were removed from the box and cultured as negative controls [25].

Enrichment culture was performed by adding $70-80 \mathrm{~mL}$ of enrichment broth consisting of $10 \mathrm{~g}$ tryptone/L, $75 \mathrm{~g}$ sodium chloride/L, $10 \mathrm{~g}$ mannitol/L, and $2.5 \mathrm{~g}$ yeast extract/L to sterile bags containing electrostatic cloths immediately following sample collection. After $24 \mathrm{~h}$ incubation at $35^{\circ} \mathrm{C}$, 1 loopful (approximately $10 \mu \mathrm{L}$ ) of broth was inoculated onto MRSA Chromogenic agar (BBL CHROMagar MRSA, Becton, Dickinson and Co., Mississauga, ON, Canada) and Mannitol Salt Agar with $2 \mu \mathrm{g} / \mathrm{mL}$ oxacillin and incubated at $35^{\circ} \mathrm{C}$ for MRSP selection. Plates were examined after 24 and $48 \mathrm{~h}$ of incubation.

Isolates were identified as $S$. aureus by colony morphology, pink color, Gram stain appearance, catalase reaction, coagulase reaction, and $S$. aureus latex agglutination test (Pastorex Staph-plus, Bio-Rad Laboratories Ltd, Mississauga, ON, Canada). Methicillinresistance was confirmed by penicillin binding protein 2a latex agglutination test (MRSA latex agglutination test, Denka Seiken, USA Inc, Campbell, CA, USA). Staphylococcus pseudintermedius was identified by colony morphology, Gram stain appearance, catalase and coagulase reactions and a species-specific non-commercialized PCR assay [28].

\section{MRSA characterization}

Isolates were typed by sequencing of the $\mathrm{X}$ region of the protein A gene (spa typing) as described [29]. For spa typing, sequences were analyzed using eGenomics software (http://tools.egenomics.com). Ridom database equivalents were identified using the Ridom Spaserver website (http:// www.spaserver.ridom.de). eGenomics spa types are reported using a numerical system (i.e. spa type 539) while Ridom spa types are reported using a numerical system preceded by a " $t$ " (i.e. spa t034). Real-time PCR was used to detect the $l u k F$ and $l u k S$ components of the Panton-Valentine leukocidin (PVL) using PVLSC-F (5'-GCTCAGGAGA TACAAG-3') and PVLSC-R (5'-GGATAGCAAAAG CAATG-3') primers [30].

\section{MRSP characterization}

MRSP isolates were characterized by sequence analysis of the mec-associated direct repeat unit ( $d r u$ typing) [31], with dru repeats and types assigned by the Dru-typing.org database (http://www.dru-typing. org/search.php).

\section{Statistical analysis}

Contamination rate data were described. Categorical associations were assessed using Fisher's exact test (FET), with significance set at $P<0.05$. Statistical analysis was performed using commercially available software (InStat, GraphPad Software Inc., La Jolla, CA, USA) 


\section{Results}

One hundred and twenty three CPs from 106 individuals were sampled. Seventy-one were personal CPs while 52 were hospital-issued CPs (Table 1). Methicillin-resistant staphylococci were isolated from 3/123 (2.4\%) CPs (Table 1). MRSP was isolated from two (1.6\%) CPs while MRSA was isolated from one $(0.8 \%)$. Both MRSP positive CPs were from samples collected on the same day and both were classified as dt9a. Samples were collected in an anonymous manner, with only identification of the personnel group (e.g. technician) so it was impossible to retrospectively investigate any potential associations between the two MRSP positive samples. Methicillin-resistant staphylococci were not isolated from any negative control samples.

The MRSA isolate was identified as spa type 18/ t338 [32]. Based on available Canadian data [32] and Ridom Spaserver website (http://www.spaserver.ridom. de), this strain was inferred to be a clonal complex 30 strain that is classified as Canadian epidemic MRSA (CMRSA)-4, USA200, and eMRSA-16. It did not contain genes encoding PVL. The MRSP isolates were identified as dru type 9a, typically associated with sequence type 71 [33].

There was no difference in contamination between different personnel classifications $(P=0.2$, FET) overall, however there was a significant difference between groups when only personal CPs were considered $(P=0.004, F E T)$ but not with hospital-issued phones $(P=0.6, \mathrm{FET})$. There was no difference overall between personal and hospital-issued phones $(P=1.0, \mathrm{FET})$.

Twenty-two percent (27/123) of sampled CPs had reportedly been disinfected in the past month. Two/27 (7.4\%) of the CPs that were contaminated had reportedly been disinfected in the past month versus $1 / 96(1.0 \%)$ that had not been disinfected $(P=0.1, \mathrm{FET})$. Sixty-four of the 71 (90\%) of individuals carrying personal CPs reported using them while on the OVCHSC premises.

Table 1 MRSA and MRSP contamination rate of personal and hospital-issued CPs by veterinary hospital personnel

\begin{tabular}{llll}
\hline Group & Personal phones & $\begin{array}{l}\text { Hospital-issued } \\
\text { phones }\end{array}$ & Total \\
\hline Technician & $2 / 8(25 \%)$ & $0 / 15$ & $\begin{array}{l}2 / 23 \\
(8.7 \%)\end{array}$ \\
\hline Residents/Interns & $0 / 8$ & $\begin{array}{l}1 / 18 \\
(5.6 \%)(\mathrm{MRSP})\end{array}$ & $\begin{array}{l}1 / 23 \\
(4.3 \%)\end{array}$ \\
\hline Veterinary student & $0 / 37$ & 0 & $0 / 37$ \\
\hline Faculty & $0 / 10$ & $0 / 13$ & $0 / 23$ \\
\hline Non-medical & $0 / 8$ & $0 / 6$ & $0 / 14$ \\
personnel & & & \\
\hline Total & $2 / 71$ & $1 / 52$ & $3 / 123$ \\
& $(2.8 \%)$ & $(1.9 \%)$ & $(2.4 \%)$ \\
\hline
\end{tabular}

\section{Discussion}

Contamination of CPs was uncommon but, nonetheless, both MRSA and MRSP were identified. These results support concerns that CPs could act as a fomite for pathogenic bacteria, with transmission to patients or personnel through subsequent contamination of the hands. The relevance of CP contamination is unclear but these data, along with similar data from human medicine raise concern [8-18]. People frequently handle CPs, and likely do so irrespective of the cleanliness of their hands. Goldblatt et al. reported that physicians used CPs excessively, even during patient contact, which likely contributed to a higher rate of $\mathrm{CP}$ contamination compared with nursing staff [18]. These factors create the potential for both contamination of the phone from contaminated hands, and transfer of pathogens from a contaminated $\mathrm{CP}$ to clean hands. Proper hand hygiene has been emphasized as a means of reducing the incidence of nosocomial infections [7] and is probably a key factor for reducing $\mathrm{CP}$ contamination. If hand hygiene is properly performed before and after patient contact, and after contact with potentially contaminated environmental sites, the risk of CP contamination would be minimized. However, hand hygiene compliance rates in human medicine remains below 50\% [34] and there is no evidence suggesting better compliance in veterinary healthcare personnel.

In a human healthcare study, physician CPs were more often contaminated than those of nursing staff $(60 \%$ vs $20 \%)$ [18]. Here, there was no significant difference overall, however there was a significant difference between groups when only personal CPs were considered, with contamination identified only on technician CPs. Reasons for this are unclear and were not specifically investigated here. It is possible that contamination could be of greater risk in technicians because they may have more contact with animals and handle more animals overall compared to the other groups. At the OVCHSC, personnel use their personal CP in the hospital and community, whereas hospital-issued CPs are used only within hospital premises. Although there was no significant difference in contamination between personal and hospital-issued CPs, further study of this association and other factors associated with CP contamination are required.

MRSP is a significant problem in companion animals, and the presence of this multidrug opportunistic pathogen is a concern [35-38]. This is not surprising since MRSP can be found in clinically normal animals [39] and in the veterinary hospital environment [40]. Considering the significant problems encountered in treating some MRSP infections, especially implant-associated surgical site infections, measures to reduce transmission of this pathogen are important. The MRSP isolates identified here were $\mathrm{dt} 9 \mathrm{a}$, which is among the most common 
dru types in North America and typically associated with sequence type 71 [33].

MRSA is both an animal health and zoonotic concern. The isolate identified here was spa type 18/t338, a human epidemic clone. Typing cannot indicate the origin of MRSA because companion animals are typically infected with human MRSA clones, and no testing of personnel was performed to differentiate animal versus human sources [20].

Only $21.9 \%$ of sampled CPs had been disinfected within the past month. Method of disinfection was not queried in the survey administered to participants. Facility infection control protocols do not address disinfection of CPs and that, combined with lack of consideration of the potential for CPs to become contaminated, may explain the low disinfection rates. There is also limited information about CP disinfection methods that are both effective and do not damage the CP. However, the use of $70 \%$ isopropyl alcohol wipes eliminated bacterial contamination in $98 \%$ of mobile phones in one study [41], and this is a simple measure that could be used routinely.

\section{Conclusions}

While uncommon, contamination of CPs with MRSA and MRSP was identified, supporting concerns that these devices may be fomites for transmission of infection to patients or personnel. Further, since personal CPs are used in the hospital and community, they represent a potential bridge between the hospital and community and could transfer zoonotic pathogens to anyone that has contact with the CP. The true risk of CP contamination is not known and whether these fomites play a role in transmission of MRSA and/or MRSP requires further investigation. Increased consideration should be given to reducing contamination, particularly avoiding handling CPs when hands might be contaminated and using good hand hygiene practices. Routine disinfection of CPs, such as with alcohol wipes, while unproven in a veterinary context, should be considered as part of a general infection control program.

\section{Competing interests}

The authors declare that they have no competing interests.

\section{Author details}

${ }^{1}$ Department of Pathobiology, Ontario Veterinary College, University of Guelph, Guelph, ON N1G 2W1, Canada. ²Department of Clinical Studies, Ontario Veterinary College, University of Guelph, Guelph, ON N1G 2W1, Canada.

\section{Authors' contributions}

TJ performed data collection and drafted the manuscript. TJ and JR performed microbiological testing. AS and JSW were responsible for study design and manuscript review. All authors read and approved the final manuscript.
Received: 07 December 2011 Accepted: 25 April 2012

Published: 25 April 2012

References

1. Faires MC, Traverse M, Tater KC, Pearl DL, Weese JS: Methicillin-resistant and -susceptible staphylococcus aureus infections in dogs. Emerg Infect Dis 2010, 16:69-75.

2. Weese JS: A review of multidrug resistant surgical site infections. Vet Comp Orthop Traumatol 2008, 21:1-7.

3. Weese JS: A review of post-operative infections in veterinary orthopedic surgery. Vet Comp Orthop Traumatol 2008, 21:99-105.

4. Owens CD, Stoessel K: Surgical site infections: epidemiology, microbiology and prevention. J Hosp Infect 2008, 70(Suppl 2):3-10.

5. Hardy KJ, Oppenheim BA, Gossain S, Gao F, Hawkey PM: A study of the relationship between environmental contamination with methicillin-resistant Staphylococcus aureus (MRSA) and patients' acquisition of MRSA. Infect Control Hosp Epidemiol 2006, 27:127-132.

6. Marshal BM, Ochieng DJ, Levy SB: Commensals: unappreciated reservoir of antibiotic resistance. Microbe 2009, 4:231-238

7. Allegranzi B, Pittet D: Role of hand hygiene in healthcare associated infection prevention. J Hosp Infect 2009, 73:305-315.

8. Brady RRW, Verran J, Daman NN, Gibb AP: Review of mobile communication devices as potential reservoirs of nosocomial pathogens. J Hosp Inf 2009, 41:295-300.

9. Brady RRW, Fraser SF, Dunlop MG, Paterson-Brown S, Gibb AP: Bacterial contamination of mobile communication devices in the operative environment. J Hosp Infect 2007, 66:397-398.

10. Karabay O, Kocoglu E, Tahtaci M: The role of mobile phones in the spread of bacteria associated with nosocomial infections. J Infect Developing Countries 2007, 1:72-73.

11. Khivsara A, Sushma T, Dhanashree B: Typing of Staphylococcus aureus from mobile phones and clinical samples. Curr Sci 2006, 90:910-912.

12. Jeske HC, Tiefenthaler W, Hohlrieder M, Hinterberger G, Benzer A: Bacterial contamination of anaesthetist's hands by personal mobile phone and fixed phone use in the operating theatre. Anaesthesia 2007, 62:904-906.

13. Borer A, Gilad J, Smolyakov R: Cell phones and Acinetobacter transmission. Emerg Infect Dis 2005, 11:1160-1161.

14. Jayalakshmi J, Appalaraju B, Usha S: Cell phones as reservoir of nosocomial pathogens. J Assoc Physicians India 2008, 56:388-389.

15. Hassoun A, Vellozi EM, Smith MA: Colonization of personal digital assistants carried by healthcare professionals. Infect Control Hosp Epidemiol 2004, 25:1000-1001.

16. Tekerekoglu MS, Duman Y, Serindag A, Cuglan SS, Kaysadu H, Tunc $E_{\text {, }}$ Yakupogullari Y: Do mobile phones of patients, companions and visitors carry multidrug-resistant hospital pathogens? Am J Infect Control 2011, 39:379-381.

17. Sadat-Ali M, Al-Omran AK, Azam Q, Bukari H, Al-Zahrani AJ, Al-Turki RA, Al-Omran AS: Bacterial flora on cell phones of health care providers in a teaching institution. Am J Infect Control 2010, 38:404-405.

18. Goldblatt JG, Krief I, Klonsky T: Use of cellular telephones and transmission of pathogens by medical staff in New York and Israel. Infect Control Hosp Epidemiol 2007, 28:500-503.

19. Klevens RM, Morrison MA, Nadle J, Petit S, Gershman K, Ray S, Harrison LH, Lynfield R, Dumyati G, Townes JM, Craig AS, Zell ER, Fosheim GE, McDougal LK, Carey RB, Fridkin SK, Active Bacterial Core surveillance MRSA investigators: Invasive methicillin-resistant Staphylococcus aureus infections in the United States. JAMA 2007, 298:1763-1771.

20. Weese JS, van Duijkeren E: Methicillin-resistant Staphylococcus aureus and Staphylococcus pseudintermedius in veterinary medicine. Vet Microbiol 2010, 140:418-429.

21. Loeffler A, Pfeiffer DU, Lloyd DH, Smith H, Soares-Magalhaes R, Lindsay JA: Methicillin-resistant Staphylococcus aureus carriage in UK veterinary staff and owners of infected pets: new risk groups. J Hosp Infect 2010, 74:282-288.

22. Burstiner LC, Faires M, Weese JS: Methicillin-resistant Staphylococcus aureus colonization in personnel attending a veterinary surgery conference. Vet Surg 2010, 39:150-157.

23. Griffeth GC, Morris DO, Abraham JL, Shofer FS, Rankin SC: Screening for skin carriage of methicillin-resistant coagulase-positive staphylococci and Staphylococcus schleiferi in dogs with healthy and inflamed skin. Vet Dermatol 2008, 19:142-149. 
24. Onuma K, Tanabe T, Sato H: Antimicrobial resistance of Staphylococcus pseudintermedius isolates from healthy dogs and dogs affected with pyoderma in Japan. Vet Dermato/ 2011. doi:10.1111/j.1365-3164.2011.00995.x [Epub ahead of print]

25. Burgess BA, Morley PS, Hyatt DR: Environmental surveillance for Salmonella enterica in a veterinary teaching hospital. J Am Vet Med AssoC 2004, 225:1344-1348.

26. Hoet AE, Johnson A, Nava-Hoet RC, Bateman S, Hillier A, Dyce J, Gebreyes WA, Wittum TE: Environmental methicillin-resistant Staphylococcus aureus in a veterinary teaching hospital during a nonoutbreak period. Vect Zoonot Dis 2011, 11:609-615.

27. Murphy CP, Reid-Smith RJ, Boerlin P, Weese JS, Prescott JF, Janecko N, Hassard $L$, McEwen SA: Escherichia coli and selected veterinary and zootnotic pathogens isolated from environmental sites in companion animal veterinary hospitals in southern Ontario. Can Vet J 2010, 51:963-972.

28. Sasaki T, Tsubakishita S, Tanaka Y, Sakusabe A, Ohtsuka M, Kawakami T, Fukata T, Hiramatsu K: Multiplex-PCR method for species identification of coagulase-positive staphylococci. J Clin Microbiol 2010, 48:765-769.

29. Shopsin B, Gomez M, Montgomery SO, Smith DH, Waddington M, Dodge DE, Bost DA, Riehman M, Naidich S, Kreiswirth BN: Evaluation of protein A gene polymorphic region DNA sequencing for typing of Staphylococcus aureus strains. J Clin Microbiol 1999, 37:3556-3563.

30. Rankin S, Roberts S, O'Shea K, Maloney D, Lorenzo M, Benson CE: Panton-Valentine leukocidin (PVL) toxin positive MRSA strains isolated from companion animals. Vet Microbiol 2005, 108:145-148.

31. Goering RV, Morrison D, Al-Doori Z, Edwards GF, Gemmell CG: Usefulness of mec-associated direct repeat unit(dru) typing in the epidemiological analysis of highly clonal methicillin-resistant Staphylococcus aureus in Scotland. Clin Microb Infect 2008, 14:964-969.

32. Golding GR, Campbell JL, Spreitzer DJ, Veyhl J, Surynicz K, Simor A, Mulvey MR, Canadian Nosocomial Infection Surveillance Program: A preliminary guideline for the assignment of methicillin-resistant Staphylococcus aureus to a Canadian pulsed-field electrophoresis epidemic type using spa typing. Can J Infect Dis Med Microbiol 2008, 9:273-281.

33. Kadlec K, Schwarz S, Weese JS: Evaluation of direct repeat unit (dru) typing for characterization of methicillin-resistant Staphylococcus pseudintermedius. In $2^{\text {nd }} A S M / E S C M I D$ conference on methicillin-resistant staphylococci in animals: veterinary and public health implications: 8-11 September 2011; Washington

34. McGuckin M, Waterman R, Govednik J: Hand hygiene compliance rates in the United States - a one-year multicenter collaboration using product/volume usage measurement and feedback. Am J Med Qual 2009, 24:205-213.

35. van Duijkeren E, Houwers DJ, Schoormans A, Broekhuizen-Stins MJ, Ikawaty R, Fluit AC, Wagenaar JA: Transmission of methicillin-resistant Staphylococcus intermedius between humans and animals. Vet Microbiol 2008, 128:213-215.

36. Laarhoven LM, de Heus P, van Luijn J, Duim B, Wagenaar JA, van Duijkeren E: Longitudinal study on methicillin-resistant staphylococcus pseudintermedius in Households. PLoS One 2011, 6:e27788.

37. Frank LA, Kania SA, Kirzeder EM, Eberlein LC, Bernis DA: Risk of colonization or gene transfer to owners of dogs with methicillin-resistant Staphylococcus pseudintermedius. Vet Dermatol 2009, 20:496-501.

38. Perreten V, Kadlec K, Schwarz S, Grönlund Andersson U, Finn M, Greko C, Moodley A, Kania SA, Frank LA, Bemis DA, Franco A, lurescia M, Battisti A, Duim B, Wagenaar JA, van Duijkeren E, Weese JS, Fitzgerald JR, Rossano A, Guardabassi L: Clonal spread of methicillin-resistant Staphylococcus pseudintermedius in Europe and North America: an international multi-center study. J Antimicrob Chemother 2010, 65:1145-1154

39. Murphy C, Reid-Smith RJ, Prescott JF, Bonnett BN, Poppe C, Boerlin P, Weese JS, Janecko N, McEwen SA: Occurrence of antimicrobial resistant bacteria in healthy dogs and cats presented to private veterinary hospitals in southern Ontario: a preliminary study. Can Vet J 2009, 50:1047-1053.

40. Nienhoff U, Kadlec K, Chaberny IF, Verspohl J, Gerlach GF, Kreienbrock L, Schwarz S: Methicillin-resistant Staphylococcus pseudintermedius among dogs admitted to a small animal hospital. Vet Microbiol 2011, 150:191-197.

41. Arora U, Devi P, Chadha A, Malhotra S: Cellphones a modern stayhouse for bacterial pathogens. JK Science 2009, 11:127-129.

doi:10.1186/1756-0500-5-193

Cite this article as: Julian et al.: Methicillin-resistant staphylococcal contamination of cellular phones of personnel in a veterinary teaching hospital. BMC Research Notes 2012 5:193.

\section{Submit your next manuscript to BioMed Central and take full advantage of:}

- Convenient online submission

- Thorough peer review

- No space constraints or color figure charges

- Immediate publication on acceptance

- Inclusion in PubMed, CAS, Scopus and Google Scholar

- Research which is freely available for redistribution 